\title{
Evaluation of acute scrotum in our consecutive operated cases: a one-center study
}

This article was published in the following Dove Press journal:

International Journal of General Medicine

15 January 2014

Number of times this article has been viewed

\section{Mohammad Kazem Moslemi Sharifeh Kamalimotlagh \\ Department of Urology, Kamkar Hospital, School of Medicine, Qom University of Medical Sciences, Qom, Iran}

Purpose: The purpose of the present study was to evaluate the clinical history, demographic data, surgical exploration findings, and final diagnoses in all young males presenting with acute scrotum to our center.

Materials and methods: This was a descriptive-retrospective study in which all consecutive cases of acute scrotum treated in our department from March 2008 to March 2012 were evaluated.

Results: A total of 116 cases were included in the study. Out of these cases, 100 cases underwent surgical exploration, and the remaining 16 cases were managed conservatively. Our eligible cases were divided into three groups: the testicular torsion (TT) group (68\%); the torsion of the appendix testis (AT) group (20\%); and the epididymo-orchitis (EO) group (9\%). Testicular preservation was achieved in 39 cases of the TT group, while due to delayed referral, orchiectomy was performed in 29 cases. Thus, our testicular salvage rate was $57.5 \%$ and missed testicular torsion rate was $42.5 \%$.

Conclusion: It was observed that our testicular salvage rate was lower than the expected figures published in the literature. This is may be attributed to different causes, including delayed referral or presentation of acute scrotum cases, inadequate knowledge of the general practitioners working in emergency departments, or poor knowledge of parents.

Keywords: epididymo-orchitis, testicular appendage, testicular torsion, missed testicular torsion, testicular salvage rate

\section{Introduction}

One of the common problems in emergency departments is acute scrotum, or testicular pain. ${ }^{1}$ The differential diagnosis between testicular torsion (TT) and the other causes of acute scrotum is critically important for the preservation of the affected testis. A torsion of the testis with rotation of the spermatic cord is a surgical emergency and needs emergency diagnosis and treatment. ${ }^{2}$ Its incidence is one in every 4,000 males younger than 25 years. ${ }^{3}$ The clinical signs of TT, epididymo-orchitis (EO), and torsion of the appendix testis (AT) are similar, and in the majority of cases, exact preoperative clinical diagnoses are very difficult.

TT was described first by Hunter in $1776 .{ }^{2}$ It most commonly occurs in adolescence but can be seen at any age. ${ }^{4}$ The salvage rate is high if the treatment begins before 6 hours after onset of the symptoms. The salvage rate decreases dramatically after later treatment. ${ }^{2}$

In this retrospective study, we evaluated the true incidence of the various causes of acute scrotum in our consecutive cases of acute scrotum, after surgical exploration, and compared their historical features and demographic data.
Moslemi

Department of Urology, Kamkar

Hospital, School of Medicine,

Qom University of Medical Sciences,

Qom, 37I5694978 Iran

Tel +989122521646

Email mkmoslemi@gmail.com
International Journal of General Medicine 2014:7 75-78 (c) (i) (8) 2014 Moslemi and Kamalimotlagh. This work is published by Dove Medical Press Limited, and licensed under Creative Commons Attribution - Non Commercial (unported, v3.0) Cicense. The full terms of the License are available at http://creativecommons.org/licenses/by-n/3.0/. Non-commercial uses of the work are permitted without any further permission from Dove Medical Press Limited, provided the work is properly attributed. Permissions beyond the scope of the License are administered by Dove Medical Press Limited. Information on how to request permission may be found at: http://www.dovepress.com/permissions.php 


\section{Materials and methods}

\section{Study design}

This was a retrospective study, from March 2008 to March 2012, in which 116 cases of acute scrotum admitted to the Kamkar Hospital, Qom, Iran were evaluated. The Kamkar Hospital in the Qom province provides secondary- and tertiary-level pediatric urology care. The general physicians and then general urologists evaluated all the patients. The case notes of all the operated patients with acute scrotum were selected for evaluation. The data were evaluated using operating theater notes, patient charts and the ninth revision of the International Classification of Disease (ICD-9). Patients' ages, clinical findings, duration of pain, location of the involvement, final diagnosis, and type of surgery were evaluated. All suspicious cases were examined by the general practitioner on duty at the emergency room, and for the uncertain cases, the general practitioner consulted with an on-call urologist. After primary evaluations and according to hospital guidelines, all patients presenting with symptoms or signs of local acute scrotum, such as hemiscrotal pain, swelling, redness and tenderness, absence of cremasteric reflex, and a clinical suspicion of TT, underwent scrotal exploration, emergently. In all cases, a complete blood count (CBC) and urinalysis (U/A) were requested. Depending on the patient's history or suspicious physical findings and the availability of a radiologist, testicular vascular Doppler ultrasonography was also requested. The presence of systemic signs and symptoms of EO, such as fever, local physical findings, and leukocytosis or pyuria and bacteriuria were excluding data for surgical exploration. All of the operated patients received analgesics, and in the case of EO, intravenous and/or oral antibiotics were prescribed. The cases with missed testicular torsion (MTT) are those cases with acute scrotum that had a late presentation or physician misdiagnosis and hence underwent orchiectomy due to unsalvageable testes.

\section{Statistical analysis}

The statistical analysis was done using the Statistical Package for Social Sciences, version 16 (IBM Corporation, Armonk, NY, USA). The data were presented as the mean \pm standard deviation (SD) and range. The differences between groups were calculated using the Student's $t$-test and the MannWhitney-Wilcoxon test (for multivariate analysis).

\section{Results}

For the 4-year period of study, the data of 116 eligible cases with acute scrotum were evaluated. In all, 100 cases were treated and included in the study. The patients were divided into three groups: the TT group; the EO group; and the AT group. The ages of the study population is presented in Table 1 . The mean age was $15.1 \pm 6.70$ years (range: $1-29$ years).

After surgical exploration, 68 cases $(68 \%)$ were found to have TT; of these, 29 cases (42.5\%) had MTT and due to nonviable testis, had orchiectomy performed. In the remaining 39 cases $(57.5 \%)$, the testis was considered viable and subdartos orchiopexy was performed. In one case of the TT group, a one-year-old infant, a MTT of a left undescended testis occurred, and orchiectomy was performed. AT was seen in 20 cases (20\%), EO in nine cases (9\%), nonspecific scrotal pain in two cases ( $2 \%)$, and a testicular hematoma in one case (1\%). All the diagnoses were determined from the results of the surgical exploration.

In the group of patients with TT (68), left side TT occurred in 38 cases (56\%) and right side TT in 30 cases (44\%) (Table 1).

In the TT group (68 cases), 21 cases (31\%) presented to hospital within the "golden" time limit (less than 6 hours after pain onset), and all of the MTT cases presented more than 18 hours (range: 18-96 hours) after pain onset (Table 2). It is noteworthy that in two cases $(2.94 \%)$ of the TT group with a late presentation of more than 18 hours, the testicles were salvaged. In the group of AT, $45 \%$ presented less than 6 hours after pain onset. In the EO group, 20\% returned less than 6 hours after pain onset, and $60 \%$ returned more than 96 hours after pain onset.

The average age of patients with TT, AT, and EO were $16.71,9.65$, and 13.13 years, respectively. In the TT group; $22 \%$ were less than 10 years of age, $58 \%$ were $11-20$ years, and $20 \%$ were more than 21 years. Sixty-five percent of the AT group were less than 10 years of age. The peak incidence of TT was between 14-18 years, while the peak for AT was slightly less than 10 years $(P<0.05)$. Using the Mann-Whitney $U$-test, there was no statistically significant

Table I The age distribution of our eligible cases

\begin{tabular}{ll}
\hline TT* & $68(\mathrm{I}-29, \mathrm{I}$ I6.7 I \pm 6.12$)$ \\
Rt TT** & $30(44 \%)$ \\
Lt TT** & $38(56 \%)$ \\
Torsion of appendix* & $20(\mathrm{I}-27,9.65 \pm 6.35)$ \\
Epididymo-orchitis* & $9(\mathrm{I}-20, \mathrm{I} 3.13 \pm 5.9 \mathrm{I})$ \\
Nonspecific scrotal pain* & $2(\mathrm{I}-20, \mathrm{I} .5 \pm 0.707)$ \\
Testicular hematoma & $\mathrm{I}(\mathrm{I}$ year $)$ \\
Total & 100 cases \\
\hline
\end{tabular}

Notes: *Data are presented as numbers of cases (age range, mean of age \pm SD); **data are expressed as $\mathrm{n}(\%)$.

Abbreviations: SD, standard deviation; TT, testicular torsion; Rt, right; Lt, left. 
Table 2 Pain duration, between onset of pain and surgery, in our cases of TT

\begin{tabular}{ll}
\hline Time interval & Value \\
\hline$<6 \mathrm{~h}$ & $21(31 \%)$ \\
$6-12 \mathrm{~h}$ & $3(4.41 \%)$ \\
$12-18 \mathrm{~h}$ & $2(2.94 \%)$ \\
$18-24 \mathrm{~h}$ & $11(16.17 \%)$ \\
$24-48 \mathrm{~h}$ & $12(17.64 \%)$ \\
$48-72 \mathrm{~h}$ & $9(13.23 \%)$ \\
$>96 \mathrm{~h}$ & $12(17.64 \%)$ \\
Total & $68(100 \%)$ \\
\hline
\end{tabular}

Notes: $\mathrm{N}=74$. Data are presented as number of cases (\%).

Abbreviations: TT, testicular torsion; $h$, hours.

difference in the mean age at presentation between the groups of TT and EO $(P>0.05)$, but the difference in age at presentation between the AT group and other two groups was significant $(P<0.05)$.

A $\mathrm{CBC}$ and U/A were performed for all the admitted cases. All of the CBC and U/A results in the TT and AT groups were unremarkable. In the EO group, there were six cases of pyuria and bacteriuria, and of mild leukocytosis detected in the CBC.

A color Doppler ultrasound was performed in 18 cases (26.5\%) of the TT group, and orchiectomy was performed in 14 of these cases. In all of them, the ultrasound study was accurate in the expression of absent testicular artery blood flow.

\section{Discussion}

The most common causes of acute scrotum are TT, EO, and AT. ${ }^{5}$ The clinical management of childhood acute scrotum depends mainly on the history and physical examination findings. In suspicious cases, the use of imaging studies, such as Doppler scrotal ultrasonography and/or radionuclide testicular scanning, may be of help for the early detection of TT.

The presence of nausea and vomiting, duration of pain of less than 24 hours, high-lying testis, and abnormal cremasteric reflex have been associated with a higher incidence of TT. ${ }^{6}$

More than half of boys with acute scrotum have AT. They are younger than those with TT, and the duration of symptoms are longer. ${ }^{7} \mathrm{EO}$ is infrequent in children and teenagers, and it accounted for $9 \%$ in our series and $16 \%$ in a study by Mushtaq et al. ${ }^{7}$

Murphy et $\mathrm{al}^{,}{ }^{8}$ in a review of over 121 cases with acute scrotum, found that the clinical findings and also Doppler ultrasonography could not differentiate between the multiple causes of acute scrotum and concluded that early surgical intervention is mandatory in all cases of pediatric acute scrotum.
The incidence of TT among the various causes of acute scrotum has varied largely in published articles, from $17 \%-72 \% .^{4,7,9,10}$ Additionally, the proportions $>25 \%{ }^{11}$ and $<5 \%{ }^{6}$ have also been reported. In the present study, TT occurred in $68 \%$ of cases, whereas in the other cases of acute scrotum, EO occurred in 9\% and AT occurred in 20\%. Our results for TT were higher but for EO were lower than in most studies. ${ }^{5,10}$ This difference may be due to accurate ruling out of EO by physical examination and the use of laboratory tests. However, the fact that our exact diagnosis of TT was mostly by surgical exploration, and not by para-clinical evaluations, may have introduced a bias into our study.

Ciftci et $\mathrm{al}^{12}$ found that patients with TT were the eldest and that their presentation was the earliest in comparison with the other two groups.

Kass et al, ${ }^{13}$ in a studies of over 77 cases, found that there is no necessity for routine surgical exploration of all children with acute scrotum. But in one-third of cases, the differential diagnosis of acute scrotum by history and physical examination is difficult and requires a rapid diagnostic tool. ${ }^{14}$

Khaleghnezhad-Tabari and Baghaeipour, ${ }^{15}$ and Khaleghnejad-Tabari et $\mathrm{al}^{16}$ in their studies of over 83 children found that TT occurred in 37\% and AT in 17\%. In the first study, orchiectomy was done in ten cases (32\%) and testicular appendectomy in 14 cases (17\%). Of those cases, $80 \%$ presented more than 8 hours after the onset of symptoms. The testis preservation rate was $68 \%$, while it was $58.5 \%$ in our study. ${ }^{15}$ The authors of the second study concluded that early surgical exploration is a safe and simple procedure and prevents the unnecessary orchiectomy that occurs when diagnosis is delayed by diagnostic imaging techniques. ${ }^{16}$

Mahdavi et al, ${ }^{17}$ in their study of over 58 cases, found that orchiectomy was carried out in $29.5 \%$ of cases. Surgical exploration was done in $71.5 \%$ of cases, and the remaining cases were managed conservatively. TT was seen in $76 \%$ (44 cases) and AT in 24\% (14 cases). Their figures were nearly the same as in our study.

Overall, the testis salvage rate was $70 \%$ in the study by Mushtaq et $\mathrm{al}^{7}$ and was reported as $62 \%-85 \%$ in another study, ${ }^{18}$ while it was $57.5 \%$ in our series.

\section{Conclusion}

One of the major issues in the management of acute scrotum is the need to increase the knowledge of the public about it. The early referral of acute scrotum cases has a key role in its early and proper management. Examination by an experienced urologist may decrease the unnecessary harms caused by its late diagnosis or misdiagnosis. Our rate of 
testicular salvage was lower than in other studies, therefore, we conclude that increasing the knowledge of general practitioners about acute scrotum is recommended. Based on our findings, the 6-hour "golden" time limit is not fixed and even in a late presentation of more than 18 hours, the testicles may be salvageable. However, in late acute scrotum presentations, emergent scrotal exploration is warranted.

\section{Disclosure}

The authors report no conflicts of interest in this work.

\section{References}

1. Corbett HJ, Simpson ET. Management of the acute scrotum in children. ANZ J Surg. 2002;72(3):226-228.

2. Boettcher M, Bergholz R, Krebs TF, Wenke K, Aronson DC. Clinical predictors of testicular torsion in children. Urology. 2012;79(3):670-674.

3. Drlík M, Kočvara R. Torsion of spermatic cord in children: a review. J Pediatr Urol. 2013;9(3):259-266.

4. Yang C, Song B, Tan J, Liu X, Wei GH. Testicular torsion in children: a 20-year retrospective study in a single institution. ScientificWorldJournal. 2011;11:362-368.

5. McAndrew HF, Pemberton R, Kikiros CS, Gollow I. The incidence and investigation of acute scrotal problems in children. Pediatr Surg Int. 2002;18(5-6):435-437.

6. Beni-Israel T, Goldman M, Bar Chaim S, Kozer E. Clinical predictors for testicular torsion as seen in the pediatric ED. Am J Emerg Med. 2010;28(7):786-789.

7. Mushtaq I, Fung M, Glasson MJ. Retrospective review of pediatric patients with acute scrotum. ANZ J Surg. 2003;73(1-2):55-58.
8. Murphy FL, Fletcher L, Pease P. Early scrotal exploration in all cases is the investigation and intervention of choice in the acute paediatric scrotum. Pediatr Surg Int. 2006;22(5):413-416.

9. Cavusoglu YH, Karaman A, Karaman I, et al. Acute scrotum-etiology and management. Indian J Pediatr. 2005;72(3):201-203.

10. Van Glabeke E, Khairouni A, Larroquet M, Audry G, Gruner M. Acute scrotal pain in children: results of 543 surgical explorations. Pediatr Surg Int. 1999;15(5-6):353-357.

11. Mäkelä E, Lahdes-Vasama T, Rajakorpi H, Wikström S. A 19-year review of paediatric patients with acute scrotum. Scand J Surg. 2007;96(1):62-66.

12. Ciftci AO, Senocak ME, Tanyel FC, Büyükpamukçu N. Clinical predictors for differential diagnosis of acute scrotum. Eur J Pediatr Surg. 2004;14(5):333-338.

13. Kass EJ, Stone KT, Cacciarelli AA, Mitchell B. Do all children with an acute scrotum require exploration? J Urol. 1993;150(2 Pt 2): 667-669.

14. Asgari SA, Mokhtari G, Falahatkar S, et al. Diagnostic accuracy of $\mathrm{C}$-reactive protein and erythrocyte sedimentation rate in patients with acute scrotum. Urol J. 2006;3(2):104-108.

15. Khaleghnezhad-Tabari A, Baghaeipour MR. Surveying the acute scrotum in children. Pejouhandeh. 2001;6(1(21)):71-74.

16. Khaleghnejad-Tabari A, Mirshermirani A, Rouzrokh M, et al. Early exploration in the management of acute scrotum in children. Iran $J$ Pediatr. 2010;20(4):466-470.

17. Mahdavi R, Ghorbani HR. Assessment of patients with testicular torsion and torsion of appendages. Medical J Mashhad Univ Med Sci. 2001;43(70);76-84.

18. Anderson JB, Williamson RC. Testicular torsion in Bristol: a 25-year review. Br J Surg. 1988;75(10):988-992.
International Journal of General Medicine

\section{Publish your work in this journal}

The International Journal of General Medicine is an international, peer-reviewed open-access journal that focuses on general and internal medicine, pathogenesis, epidemiology, diagnosis, monitoring and treatment protocols. The journal is characterized by the rapid reporting of reviews, original research and clinical studies across all disease areas.

\section{Dovepress}

A key focus is the elucidation of disease processes and management protocols resulting in improved outcomes for the patient.The manuscript management system is completely online and includes a very quick and fair peer-review system. Visit http://www.dovepress.com/ testimonials.php to read real quotes from published authors. 